\title{
correspondence
}

\section{EEC directives}

SIR,-In his article "A community of interests" (October 16), Lord Ashby describes as "phoney" the EEC argument that to permit lower effluent standards to a Scottish wood pulp mill than to one situated on the Rhine constitutes unfair competition.

The EEC argument is valid since the clear intention of the 1973 Declaration is to remove the question of pollution control from the realm in which market forces can operate. The situation is analogous to that of safety regulations inside the suggested wood pulp mills. Such regulations are recognised as imposing a prior cost on the production process. Society, through the legislative process, has opted for such. Price competition can begin after these legislated costs have been paid-and a company can only stay in business if its rivals are obliged to do the same.

London, UK

\section{B. A. Mardall}

SIR,-Regarding Lord Ashby's article on EEC directives and pollution, there is surely now real evidence that sewage in seawater around beaches is dangerous to health. I refer to work by $\mathrm{Dr} H$. Williams Smith, a bacteriologist, who analysed samples of seawater from fifteen beaches in England and Wales, and found high concentrations of $E$. coli which had clearly got there from sewage. As Dr Smith pointed out in 1971, this could lead to $E$. coli (which are themselves harmless) being swallowed while swimming and passing on the property of resistance to antibiotics to bacteria in the swimmer's gut.

\section{$B B C$, London, $U K$}

JoHN NEWELL

\section{The science of astrology?}

SIR,-Although one can deplore the mumbo-jumbo of astrology and its patently false postulate that planetary and stellar positions are relevant to the human condition, the condemnation of it in immoderate terms by 186 scientists (September 18) could well prove equally deplorable. It should be remembered that modern chemistry springs from alchemy, beside which astrology seems almost rational!

Perhaps astrology, like alchemy, represents a corpus of observational data collected over millennia which has not yet been codified. It is entirely credible that a foetus conceived in winter will differ (on account of maternal stress from the environment) from one conceived in summer, and the difference might have behavioural implications. If so, astrology could prove to be a repository of data, access to which is attained by what is virtually an elaborate calendar.

Anthropological or social-science studies along these lines might be profitable; certainly without them outright condemnation is rash.

Epsom, UK

\section{S. SMITH}

\section{Botanical decline}

SIR,-The declining interest in the botanical sciences is causing concern to biologists, and especially plant scientists all over the world. The implications of declining interest in plants are far reaching, particularly when the need for increasing food supplies becomes more and more urgent. It is therefore of interest to see how the plant sciences are represented in a general science journal such as Nature. Without claiming to have made a statistically significant study, I think the following figures are striking indeed, I counted the biologically oriented Letters to Nature in 10 recent issues of Nature. In 10 issues there were 236 such communications. Of these, 14 dealt with subjects which may be regarded as botanical in the wide sense of the word. Of these 14, two dealt with photosynthesis, three with plant biochemistry and four with fungal metabolism.In other words, the entire area of plant sciences is represented by not quite $6 \%$ of the letters to Nature. The results of this are of course obvious. Plant scientists being aware of the few botanically oriented articles in Nature will respond in two ways. They will tend not to read Nature, a fact easily confirmed by casual consultation of colleagues. In addition they will tend not to send papers to Nature, because they will readily be overlooked by those most interested.

The existence of fashions in science is well known. What is perhaps not always appreciated is just how invidious the effects of such fashions are. A fashion will lead to increased publication, which in turn draws increasingly the attention of those not working on well defined, clearly oriented problems. Such new criteria as citation indexes aggravate this. One should also not ignore the repercussions which publication policies have on the availability of research funds. The problem of fashion exists, of course, not only in general science journals but also in specialised ones. Very often the disastrous results are not due to any deliberate editorial policy but to a snowball effect. Articles in a fashionable field will lead to an increasing volume of articles in the same area. It may be assumed that the number of good articles will be greater, the great the number of articles submitted (although this will certainly not be a linear relation). It is then inevitable that articles on fashionable subjects will flood the journals and decrease the interest in less fashionable subjects.

A. M. MAYER

The Hebrew University of Jerusalem, Israel

\section{Cats' eyes: a new twist?}

SIR, - Dr Blakemore's work on the rotation of kitten's eyes has-quite rightly_raised a storm of protest and we in the RSPCA are obviously extremely concerned at any suggestion that physical or psychological suffering has been inflicted, to whatever degree.

What also concerns us is that we seem to have yet another example of unnecessary experimentation on living animals. Work by Stratton in 1897 was developed by Snyder and Pronko (1950) and others, leading to that published by Held and Baur in 1967 and subsequently.

It is now well established that no adaption occurs in the primary visual cortex when there is rotation of the visual image; and that visual perception involves the integration of both visual and non-visual activity by the higher centres.

In view of this all that Blakemore seems to have done is to have established that rotation of the retina produces similar effects to those produced by using prisms.

Why does he not admit that this was simply another ill-advised academic exercise instead of attempting 'post hoc' justifications of his 'experiments' on the ground that they will contribute to the treatment of various afflictions which are either incredibly rare, readily studied in humans or both.

D. A. Paterson

Royal Society for the Prevention

of Cruelty to Animals,

Sussex, UK 